\title{
Increased expression of a-methylacyl-coenzyme A racemase (AMACR; p504s) and p16 in distal hyperplastic polyps
}

\author{
Nimet Dayi ${ }^{1}$, Hideo A Baba ${ }^{2}$, Kurt W Schmid ${ }^{2}$ and Klaus J Schmitz ${ }^{2,3^{*}}$
}

\begin{abstract}
Background: Hyperplastic polyps (HP) and sessile serrated adenomas (SSA) share morphological similarities. In this immunohistochemical study we chose a panel of potential relevant and promising biomarkers including a-methylacyl-coenzyme A racemase (AMACR; p504s), which is involved in the degradation of branched chained fatty acids derivates, and analysed a cohort of HPs and SSAs in order to identify different immunophenotypes in relation to lesion localisation.
\end{abstract}

Methods: 154 specimen were carefully selected and a micro tissue array (TMA) was constructed. Immunohistochemistry of $16^{\text {Ink4a }}$, Ki67, a-methylacyl-coenzyme A racemase (AMACR; p504s), BRAF, CK 20, MLH1 and $\beta$-catenin was performed and and immunoexpression was compared among proximal and distal HPs as well as SSAs.

Results: None of the markers revealed a differential expression among HPs and SSAs. However, the study demonstrates a significant overexpression of AMACR $(p=0.004)$ and $p 16^{\text {Ink4a }}(p=0.028)$ in distal HPs compared to proximal HPs. In addition AMACR overexpression was associated with increased $p 16^{\text {Ink4a }}$ immunoexpression $(p<0.001)$.

Conclusions: In this study we describe differential AMACR and $p 16^{\operatorname{lnk} 4 a}$ in HPs in relation to their localisation. Distal HPs were characterized by AMACR and $\mathrm{p} 16^{\text {Ink4a }}$ overexpression in contrast to proximal HPs, although morphological identically. Thus AMACR overexpression points towards a pathobiological relevance of the protein in distal HPs. In context of recently published data this suggest distal HPs as potential precursor lesions of certain adenoma subtypes. However, at this point of time this finding remains speculative and needs to be confirmed by further studies.

Virtual slides: The virtual slide(s) for this article can be found here: http://www.diagnosticpathology.diagnomx. eu/vs/1836116001066768

Keywords: AMACR, p16 ${ }^{\text {Ink4a }}$, Hyperplastic polyp, Sessile serrated adenoma

\section{Background}

Historically hyperplastic polyps have been considered benign and harmless lesions for several decades [1]. Meanwhile it is known, that besides of the classical adenomaadenocarcinoma pathway described by Vogelstein [2], an additional (non-hereditary) pathways exists, called

\footnotetext{
* Correspondence: kjschmitz@pathologie-re.de

${ }^{2}$ Institute of Pathology and Neuropathology, University of Duisburg-Essen,

Hufelandstrasse 55, 45122 Essen, Germany

${ }^{3}$ Institute of Pathology Recklinghausen, Mühlenstrasse 31, 45659

Recklinghausen, Germany

Full list of author information is available at the end of the article
}

the serrated pathway [1,3-6] resulting in serrated lesions such as the sessile serrated adenoma (SSA) and serrated adenocacinoma. The serrated morphology of this pathway reflects the disorder in impaired apoptosis resulting in retention of epithelial cells at the base of the crypts.

Molecular key features of the classical adenomaadenocarcinoma include KRAS and p53, whereas in the serrated pathway BRAF mutations appear to be an early event [2,7-9]. In addition this initial event is often followed by hypermethylation of $\mathrm{CpG}$-island in gen promoters. As a result of hypermethylation e.g. MLH1 genes are silenced

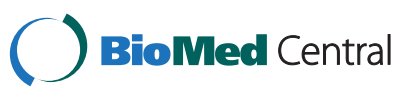


resulting in the well known and characteristic (sporadic) microsatellite instable phenotype and genotype, which often occurs in SSA and serrated adenocarcinoma [10]. Meanwhile several pathomorphogical criteria have been established, that allow a stricter separation of SSAs and hyperplastic polyps (HPs) $[3,11]$. However, clear separation of SSA and HP in individual cases is sometimes impossible. In addition, even HPs may harbour somatic BRAF mutations and an so-called CPG island methylator phenotype (CIMP) [12,13]. Thus a subset of HPs may be precursor lesions of SSAs.

The aim of this study was to analyse several immunohistochemical markers in order to 1) identify additional markers, that may allow a more clearly separation of HPs and SSAs and 2) to compare proximal and distal HPs and to work out potential different immunophenotypes of proximal versus distal HPs.

The antibodies used in this study were the following: 1) p16 ${ }^{\text {Ink4a }}$, which is an important factor in carcinogenesis and was shown to be linked to oncogene-induced senescence in the serrated route to colon cancer [14]; 2) Ki67, which represents a established proliferation marker; 3) $\alpha$-methylacyl-coenzyme A racemase (AMACR; p504s). AMACR is a mitochondrial and peroxisomal enzyme that is part of the degradation of branched chained fatty acid derivates. AMACR is essential for the completion of the $\beta$-oxidation pathway [15] and has recently been shown to upregulated in colorectal cancer and adenoma [16-18]; 4) BRAF, MLH1 and $\beta$-catenin as additional markers involved in the serrated adenocarcinoma carcinogenesis.

\section{Material and methods Specimen}

Initially 891 biopsy specimen from 2009 to 2012 representing HPs and SSAs were retrieved from the files of the Institute of Pathology, Recklinghausen. The slides of these specimen were re-evaluated by the authors KJS and ND. All biopsies, that did not allow optimal evaluation of the complete lamina propria (including the base of the crypts) were excluded from further investigation $(n=737)$. In the remaining 154 specimen, lesion localisation was defined as proximal, if retrieved from coecum or ascending colon. Distal localization included specimen derived from descending colon, sigmoid or rectum. Table 1 depicts relevant clinical data of the study group.

\section{Tissuemicroarray (TMA) construction}

SSA and HP areas were carefully selected and marked on the respective H\&E (haematoxylin and eosin-stained) slides. TMA construction was performed as previously described [19]. The TMA included 154 specimen.
Table 1 Clinical details of the study group

\begin{tabular}{lccc}
\hline Variables & \multicolumn{3}{c}{ Results } \\
\cline { 2 - 4 } & Proximal HPs & Distal HPs & SSAs \\
\hline Gender & 21 & 39 & 18 \\
Male & 27 & 28 & 14 \\
Female & 65.45 & 62.70 & 65.35 \\
Mean age in years & &
\end{tabular}

\section{Immunohistochemistry of TMA}

The primary antibodies used as well as the technical details are summarized in Table 2.

\section{Evaluation of immunohistochemistry}

AMACR: AMACR expression was scored according to the intensity of solely basal crypt cytoplasmic staining pattern. AMACR negative (0): no basal staining; AMACR positive (1+): cytoplasmic immunostaining of basal located crypt epithelial cells, independent of the intensity.

P16: p16 expression was scored according to the intensity of solely basal crypt nuclear and cytoplasmic staining patterns. p16 negative: missing basal immunostaining; p16 positive: basal positive nuclear and cytoplasmic staining.

Ki67: Ki67 expression was scored according to the positivity of epithelial cells in the upper third of the crypts. Positive cells were counted.

Cytokeratin 20: all cases showed an upper crypt staining and scattered basal stained cells. Cases were scored according the Cytokeratin 20 staining pattern: usual pattern (staining confined to upper crypt zone) and unusual pattern (additional scattered positivity in the basal crypt zone).

BRAF, MLH1 and $\beta$-catenin: MLH1 immunostaining revealed no morphological differences among different groups (HP versus SSA) or different localizations (proximal vs. distal). A weak MLH1 staining was noticed in all specimen. BRAF immunostaining was weak to negative in all cases (although external control specimen containing BRAF mutations resulted in positive immunostaining). $\beta$-catenin immunostaining resulted in strong cytoplasmic and nuclear staining of the complete basal crypt zone of all specimen. BRAF, MLH1 and $\beta$-catenin were excluded from further analysis.

\section{Statistical analysis}

All immunostainings were assessed by KJS and ND in a blind trial fashion. In case of disagreement, slides were re-evaluated by both investigators until agreement was reached. All data were converted to a PC and statistically analysed using SPSS version 20 for Macintosh (Statistical Package for Social Sciences, Chicago, IL, USA). Relationships between ordinal parameters were investigated using the two-tailed $x^{2}$ analysis. The relationship between categorical data (e.g. SSA versus HP) and numeric 
Table 2 Antibodies used for immunohistochemistry

\begin{tabular}{|c|c|c|c|c|c|c|}
\hline Antibody & & Pretreatment & Incubation & Detection & Dilution & Company \\
\hline AMACR & Monoclonal & $\begin{array}{l}98^{\circ} \mathrm{C} \mathrm{Hot} \\
\text { water, } \mathrm{pH} 9.0\end{array}$ & $15 \mathrm{~min}$ & Envision $^{\mathrm{TM}}$ & Ready-to-Use Kit & Dako, Glostrup, Denmark \\
\hline p16lnk & $\begin{array}{l}\text { Monoclonal, } \\
\text { clone G175-405 }\end{array}$ & $\begin{array}{l}98^{\circ} \mathrm{C} \mathrm{Hot} \\
\text { water, pH 6.1, }\end{array}$ & $20 \mathrm{~min}$ & Envision $^{\mathrm{TM}}$ & $1: 10$ & $\begin{array}{l}\text { BD Biosciences, } \\
\text { Heidelberg, Germany }\end{array}$ \\
\hline Ki67 & $\begin{array}{l}\text { Monclonal, clone } \\
\text { MIB-1 }\end{array}$ & $\begin{array}{l}98^{\circ} \mathrm{C} \mathrm{Hot} \\
\text { water, pH 9.0, }\end{array}$ & $15 \min$ & Envision $^{\mathrm{TM}}$ & Ready-to-Use Kit & Dako, Glostrup, Denmark \\
\hline BRAF & $\begin{array}{l}\text { Monoclonal, } \\
\text { clone VE1 }\end{array}$ & $\begin{array}{l}37^{\circ} \mathrm{C} \mathrm{Hot} \\
\text { water, } \mathrm{PH} 9.0\end{array}$ & $30 \mathrm{~min}$ & Envision $^{\mathrm{TM}}$ & 1:100 & $\begin{array}{l}\text { DCS Innovative Diagnostik, } \\
\text { Hamburg, Germany }\end{array}$ \\
\hline MLH1 & $\begin{array}{l}\text { Monoclonal, } \\
\text { clone ES05 }\end{array}$ & $98^{\circ} \mathrm{C}, \mathrm{pH} 9.0$ & $20 \mathrm{~min}$ & Envision $^{\mathrm{TM}}$ & Ready-to-Use Kit & Dako, Glostrup, Denmark \\
\hline Beta-catenin & Monoclonal & $\begin{array}{l}37^{\circ} \mathrm{C} \text { water } \\
\text { bath } 30 \text { min }\end{array}$ & $20 \mathrm{~min}$ & $\begin{array}{l}\text { Zytochem Plus HRP Polymer } \\
\text { (Zytomed Systems, Berlin, Germany) }\end{array}$ & $1: 2000$ & $\begin{array}{l}\text { BD Biosciences, Heidelberg, } \\
\text { Germany }\end{array}$ \\
\hline CK20 & $\begin{array}{l}\text { Monoclonal, } \\
\text { Clone Ks20.8 }\end{array}$ & $98^{\circ} \mathrm{C}, \mathrm{pH} 9.0$ & $30 \mathrm{~min}$ & Envision $^{\mathrm{TM}}$ & Ready-to-Use Kit & Dako, Glostrup, Denmark \\
\hline
\end{tabular}

data (number of Ki67 positive cells) was determined using the Kruskal Wallis test.

\section{Results}

Table 3 summarizes the amount of specimen included in this study and analysed for AMACR and p16 immunoexpression.

AMACR immunostaining was located in the cytoplasm of upper and basal crypt cells. Only basal location was analysed. Regarding the group of HPs, $\chi^{2}$ analysis showed, that distal HPs exhibited statistically significantly positive AMACR expression $(\mathrm{p}<0.004$; Table 4). Figure 1 demonstrates AMACR expression in SSA and HP.

Regarding the group of SSA, no statistically different AMACR immunoexpression could be detected among proximal and distal SSAs $(\mathrm{p}=0.329)$. In addition a comparison of all SSAs versus all HPs revealed no differences in AMACR expression ( $p=0.448)$.

P16 immunostaining was located at the basal crypt zone in the cytoplasm and nucleus of crypt cells (Figure 2). If all HPs were compared to all SSAs no statistical difference in $\mathrm{p} 16$ expression was detected $(\mathrm{p}=0.183)$. The analysis of proximal versus distal HPs demonstrated a significantly stronger p16 immunoexpression in distal HPs $(\mathrm{p}=0.028$; Table 4).

Further we analysed the association of AMACR and p16 expression within the group of HPs. There was a highly significant association of AMACR overexpression with $\mathrm{p} 16$ positivity in HPs $(\mathrm{p}<0.001$; Table 5$)$.

Table 3 Specimen analysed for AMACR and p16 immunoexpression

\begin{tabular}{|c|c|c|c|c|c|c|c|}
\hline \multirow[t]{2}{*}{ AMACR } & \multirow{2}{*}{$\frac{\mathrm{N}}{106}$} & \multicolumn{2}{|c|}{ Localization } & \multirow[t]{2}{*}{ p16 } & \multirow{2}{*}{$\frac{N}{109}$} & \multicolumn{2}{|c|}{ Localization } \\
\hline & & Distal & Proximal & & & Distal & Proximal \\
\hline HPS & 82 & 49 & 33 & HPS & 83 & 50 & 33 \\
\hline SSAS & 24 & 11 & 13 & SSAS & 26 & 12 & 14 \\
\hline
\end{tabular}

Ki67: Ki67 analysis of HPs versus SSAs and within the groups of HPs or SSAs revealed no significant results. There were no statistically significant differences between the mean Ki67 value in HPs versus SSAs. However the mean value of KI67 proliferating cells was higher in SSA compared to HP.

Cytokeratin 20: Cytokeratin 20 analysis of HPs versus SSAs and within the groups of HPs or SSAs revealed not significant results. There were no differences in the distribution of CK20 staining of the upper crypt zone and the basal zone.

MLH1: MLH1 analysis of HPs versus SSAs and within the groups of HPs or SSAs revealed not significant results. There were no differences in the distribution of MLH1 staining of the upper crypt zone and the basal zone.

Beta-catenin: analysis of HPs versus SSAs and within the groups of HPs or SSAs revealed not significant results. All cases revealed a cytoplasmic/nuclear staining at the basal crypt zone.

BRAF: All cases revealed a weak to negative staining without significant differences. All cases lacked positive staining results, although HPs frequently demonstrate BRAF mutations and despite of positive external study controls. Thus BRAF immunohistochemistry in this study is not a reliable tool to detect BRAF mutations in HPs or SSAs.

\section{Discussion}

This study on a cohort of HPs and SSAs demonstrates, that HPs exhibit different immunophenotypes regarding to their localization (proximal vs. distal). The Immunohistochemical analysis included the following markers: AMACR, p16 ${ }^{\text {Ink }}$, CK20, Ki67, BRAF, $\beta$-catenin and MLH1. We focussed on the expression of AMACR and p16 ${ }^{\text {Ink }}$ in HPs and SSAs with respect on lesion localisation since analysis of CK20, Ki67, BRAF, $\beta$-catenin and MLH1 either lacked significant results or resulted in 
Table 4 AMACR and p16 expression in proximal and distal HPs

\begin{tabular}{|c|c|c|c|c|c|c|}
\hline & \multicolumn{3}{|c|}{ AMACR $(n=82)$} & \multicolumn{3}{|c|}{$p 16(n=83)$} \\
\hline & Negative & Positive & $\overline{p \text {-value }}$ & Negative & Positive & $\overline{p \text {-value }}$ \\
\hline Proximal HPs & $28(84,8 \%)$ & $5(15,2 \%)$ & 0,004 & $31(96,6 \%)$ & $1(3,1 \%)$ & 0,028 \\
\hline Distal HPs & $27(55,1 \%)$ & $22(44,9 \%)$ & & $41(80,4 \%)$ & $10(19,6 \%)$ & \\
\hline
\end{tabular}

unreliable data. All parameters analysed are involved in the serrated adenocarcinoma pathway. Besides the well known AMACR overexpression in prostate cancer [20], overexpression was also demonstrated in colorectal cancer [21]. Moreover dysplastic epithelial cells in Barrett Oesophagus were shown to be associated with elevated AMACR levels [22].

Likewise SSAs, HPs have been shown to harbour specific genetic alterations such as somatic BRAF mutations and CPG island methylator phenotype (CIMP) [12,13]. This suggests the progression of a subset of HPs towards SSAs. Thus one of our study aims was to identify potential biomarkers, that may allow more precise separation of HPs and SSAs and identify a subset of HPs that might qualify as precursor lesions of SSAs. However, the analysed biomarkers did not provide additional diagnostic information allowing a more distinct differentiation of HPs and SSAs. Recently Ki67 counting and distribution was shown to be different in HPs versus SSAs, with higher Ki67 values in SSAs [23]. However, in our study we could not confirm this finding. This might be due to the fact, that in our study only a small number of SSAs were analysed. In addition in the study by Fujiimori et al. Ki67 evaluation was calculated using automated image processing software, whereas this was not the case in the present study.

Furthermore this study describes a significant overexpression of AMACR in left-sided distal HPs when compared to right-sided proximal HPs. Thus although morphological identically these lesions exhibit a varying AMACR immunophenotype. It is unlikely, that these distal HPs are at higher risk to progress to SSAs, since SSAs are typically located proximal in the right colon. Given the known function of AMACR regarding fat metabolism, it may be possible, that in the distal parts of the colon the mucosa is exposed to an increased amount of branched-chain fatty acids and fatty acid derivates.

Another possible explanation would be a specific supportive role of AMACR in the development of precursor lesions in the colorectal cancer carcinogenesis. This hypothesis is supported by recent data demonstrating increased AMACR expression in high grade dysplasia compared to low grade dysplasia in conventional adenomas [18].

Until now only few studies focussed on AMACR expression in gastrointestinal tumours. In a recent study

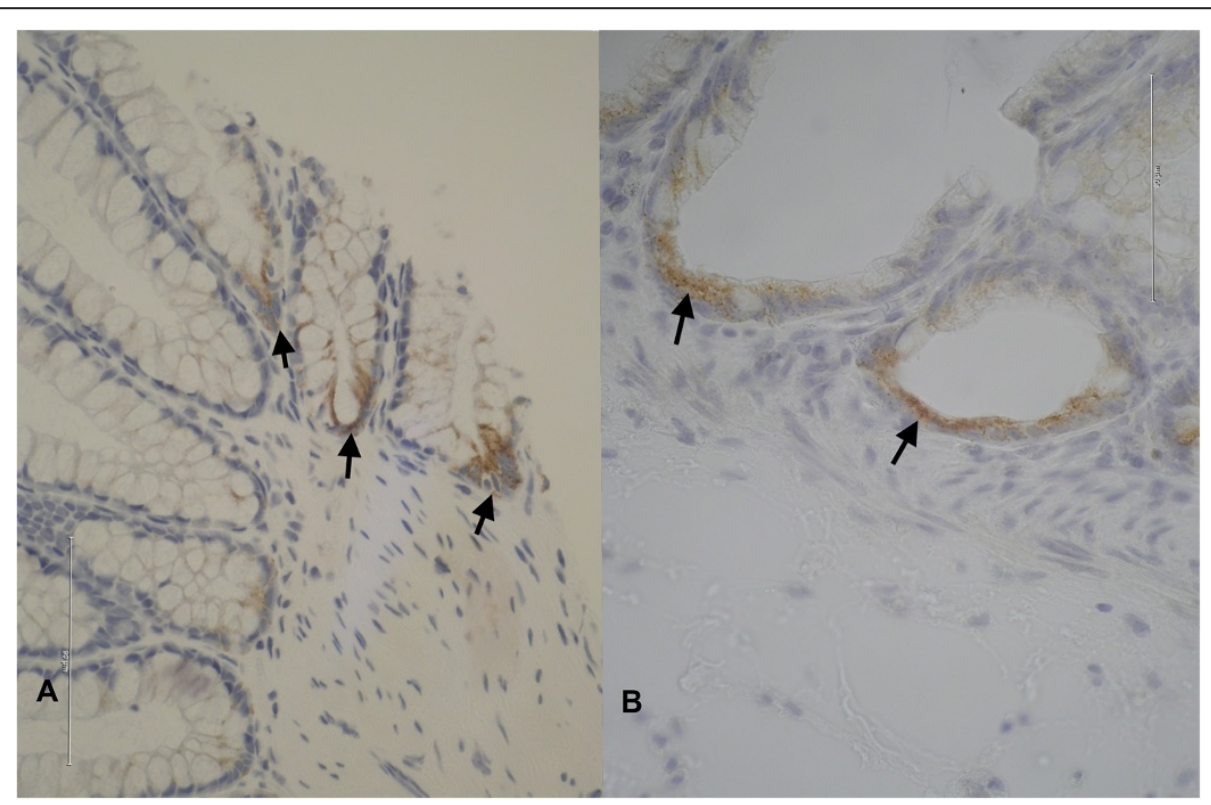

Figure 1 On the left HP with strong basal AMACR immunoexpression. On the right higher magnification of cytoplasmic granular AMACR expression at the base of the typically L-shaped, dilated SSA crypts (magnification $\times 400$ ). 


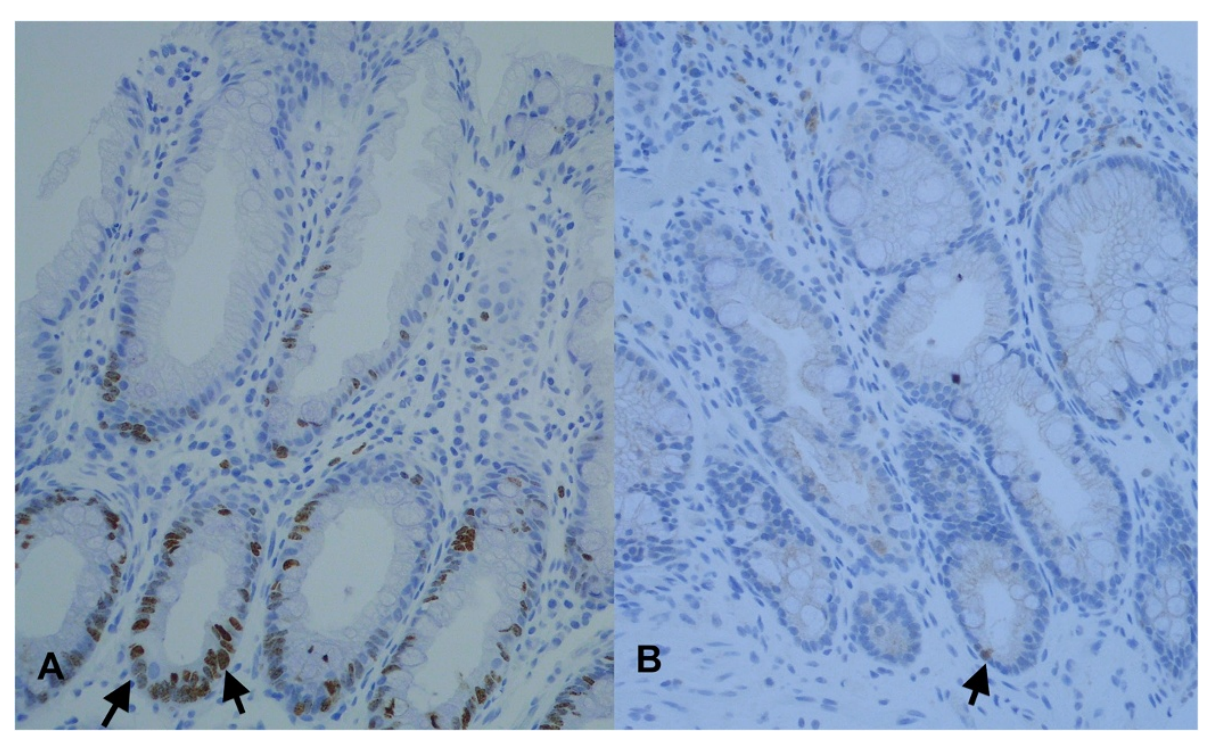

Figure 2 On the left strong nuclear p16 expression in a distal hyperplastic polyp. On the right missing to low p16 expression in a proximal HP (magnification $\times 200)$.

on 1315 colorectal cancers AMACR overexpression was found to be associated with left-side tumour localisation in colorectal cancer [16]. In detail, AMACR elevation was significantly associated with higher tumour differentiation grade (G1 and G2) and advanced tumour stage. In addition high AMACR expression levels were related to a tubular phenotype and less often to mucinous or signet cell carcinomas. These results presented by Marx et al. point towards a relevant role of AMACR expression at least in a subgroup of colorectal cancer and implicate a linkage of AMACR expression and site-related differences in metabolism/exposure to fatty acids.

In the present study in addition to differential expression of AMACR in HPs, we were able to detect significant differences in the expression of $\mathrm{p} 16^{\text {Ink4 }}$ in proximal and distal HPs. Similar to AMACR, p16 ${ }^{\text {Ink } 4}$ was overexpressed in distal HPs and significantly associated with AMACR overexpression. $\mathrm{p} 16^{\text {Ink4 }}$ is a well characterized protein with an important role in oncogene-induced cell aging $[24,25]$. Upregulation of $\mathrm{p} 16^{\text {Ink4a }}$ was recently shown to function as an senescence barrier in the serrated route to colon cancer [14].

Taken together the overexpression of AMACR and p16 ${ }^{\text {Ink }}$ in distal HPs points toward a pathophysiological relevance of both these proteins. It is now necessary to

Table 5 Association of AMACR and p16 in HPs

\begin{tabular}{llll}
\hline HPs $(\mathbf{n}=\mathbf{7 5})$ & \multicolumn{3}{l}{ p16 immunoexpression } \\
\cline { 2 - 4 } & Negative & Positive & p-value \\
\hline AMACR positive & $49(75 \%)$ & $1(9,1 \%)$ & $<0.001$ \\
AMACR negative & $27(25 \%)$ & $10(90,9 \%)$ & \\
\hline
\end{tabular}

identify in which processes AMACR and $\mathrm{p} 16^{\text {Ink }}$ in distal HPs are involved and if their dysregulation is implicated in the development of certain subgroups of adenomas.

Highly interesting in this context is a very recent study from Zhang et al. that analyses AMACR expression in normal mucosa, adenoma and colorectal carcinoma both on immunohistochemical and genetic level [17].

Zhang et al. reported AMACR negativity in normal colonic mucosa and tubular adenoma with low grade and intermediate dysplasia as well as in poorly differentiated carcinoma. In contrast AMACR overexpression was found in villous adenoma and high and moderately differentiated colon cancer. These results are in concordance with those of Marx et al. Using Laser-capture-microdissection Zhang et al. discovered different deletions in the AMACR promotor $\mathrm{CpG}$ Island, depending upon the underlying tissue: In normal colonic glands and tubular adenomas with low AMACR expression they detected a somatic doubledeletion at CG3 and CG10, that was absent in villous adenomas and all colon cancers with variable AMACR levels. In contrast they identified a high prevalence (89\%) of deletion of CG12-16 in moderately differentiated colon cancers with strong AMACR overexpression, whereas these deletions existed in only $14 \%$ of poorly differentiated colon cancer. This deletion of CG12-16 was shown to be a constitutional allele with a frequency of $43 \%$ in the general population.

Taken together, AMACR protein expression may be regulated by somatic or constitutional genetic alterations in AMACR Promoter CPG islands. Keeping the above mentioned findings in mind, it is now tempting to speculate, that distal HPs with increased AMACR expression might constitute precursor lesions of a pathway leading to the 
development of villous adenomas and/or subtypes of low grade colorectal cancers.

\section{Conclusions}

This study demonstrates differential expression of AMACR and p16 in morphologically similar looking HPs in relation to their localisation. Distal located HPs exhibit AMACR and p16 overexpression compared to proximal HPs. The reasons and pathobiologically significance of this varying immunophenotype needs be elucidated in further studies.

\section{Competing interests}

The authors declare that they have no competing interests.

\section{Authors' contributions}

ND and KJS drafted the manuscript, ND analysed Immunohistochemical data and performed TMA construction and data collection. HAB and KWS participated in the design of the study, have made substantial contributions to conception and design as was data analysis and have given final approval of the version to be published. KJS has performed statistical analysis. All authors read and approved the final manuscript.

\section{Author details}

'St. Barbara-Hospital, Barbarastrasse 1, 45964 Gladbeck, Germany. ${ }^{2}$ Institute of Pathology and Neuropathology, University of Duisburg-Essen, Hufelandstrasse 55, 45122 Essen, Germany. Institute of Pathology Recklinghausen,

Mühlenstrasse 31, 45659 Recklinghausen, Germany.

Received: 9 September 2013 Accepted: 15 October 2013

Published: 23 October 2013

\section{References}

1. Morson BC: Precancerous lesions of the colon and rectum. Classification and controversial issues. JAMA 1962, 179:316-321.

2. Fearon ER, Vogelstein B: A genetic model for colorectal tumorigenesis. Cell 1990, 61:759-767.

3. Torlakovic E, Skovlund E, Snover DC, Torlakovic G, Nesland JM: Morphologic reappraisal of serrated colorectal polyps. Am J Surg Pathol 2003, 27:65-81.

4. Torlakovic E, Snover DC: Serrated adenomatous polyposis in humans. Gastroenterology 1996, 110:748-755.

5. Jass JR, Smith M: Sialic acid and epithelial differentiation in colorectal polyps and cancer-a morphological, mucin and lectin histochemical study. Pathology 1992, 24:233-242.

6. Yao T, Nishiyama Kl, Oya M, Kouzuki T, Kajiwara M, Tsuneyoshi M: Multiple "serrated adenocarcinomas" of the colon with a cell lineage common to metaplastic polyp and serrated adenoma. Case report of a new subtype of colonic adenocarcinoma with gastric differentiation. J Pathol 2000, 190:444-449.

7. Kambara T, Simms LA, Whitehall VL, Spring KJ, Wynter CV, Walsh MD, Barker MA, Arnold S, McGivern A, Matsubara N, Tanaka N, Higuchi T, Young J, Jass $J R$, Leggett BA: BRAF mutation is associated with DNA methylation in serrated polyps and cancers of the colorectum. Gut 2004, 53:1137-1144.

8. Tateyama H, Li W, Takahashi E, Miura Y, Sugiura H, Eimoto T: Apoptosis index and apoptosis-related antigen expression in serrated adenoma of the colorectum: the saw-toothed structure may be related to inhibition of apoptosis. Am J Surg Pathol 2002, 26:249-256.

9. Jass JR, Whitehall VLJ, Young J, Leggett BA: Emerging concepts in colorectal neoplasia. Gastroenterology 2002, 123:862-876.

10. Toyota M, Ahuja N, Ohe-Toyota M, Herman JG, Baylin SB, Issa JP: CpG island methylator phenotype in colorectal cancer. Proc Natl Acad Sci U S A 1999, 96:8681-8686.

11. Baretton GB, Autschbach F, Baldus S, Blaker H, Faller G, Koch HK, Langner C, Luttges J, Neid M, Schirmacher P, Tannapfel A, Vieth M, Aust DE: [Histopathological diagnosis and differential diagnosis of colorectal serrated polys: findings of a consensus conference of the working group "gastroenterological pathology of the german society of pathology"]. Pathologe 2011, 32:76-82.
12. Carr NJ, Mahajan H, Tan KL, Hawkins NJ, Ward RL: Serrated and nonserrated polyps of the colorectum: their prevalence in an unselected case series and correlation of BRAF mutation analysis with the diagnosis of sessile serrated adenoma. J Clin Pathol 2009, 62:516-518.

13. Spring KJ, Zhao ZZ, Karamatic R, Walsh MD, Whitehall VLJ, Pike T, Simms LA, Young J, James M, Montgomery GW, Appleyard M, Hewett D, Togashi K, Jass JR, Leggett BA: High prevalence of sessile serrated adenomas with BRAF mutations: a prospective study of patients undergoing colonoscopy. Gastroenterology 2006, 131:1400-1407.

14. Kriegl L, Neumann J, Vieth M, Greten FR, Reu S, Jung A, Kirchner T: Up and downregulation of p16(Ink4a) expression in BRAF-mutated polyps/ adenomas indicates a senescence barrier in the serrated route to colon cancer. Mod Pathol 2011, 24:1015-1022.

15. Ferdinandusse S, Denis S, IJIst L, Dacremont G, Waterham HR, RJ W: Subcellular localization and physiological role of alpha-methylacyl-CoA racemase. J Lipid Res 2000, 41:1890-1896.

16. Marx A, Simon P, Simon R, Mirlacher M, Izbicki JR, Yekebas E, Kaifi JT, Terracciano L, Sauter G: AMACR expression in colorectal cancer is associated with left-sided tumor localization. Virchows Arch 2008, 453:243-248.

17. Zhang X, Leav I, Revelo MP, Deka R, Medvedovic M, Jiang Z, Ho S-M: Deletion hotspots in AMACR promoter CpG island are cis-regulatory elements controlling the gene expression in the colon. PLoS Genet 2009, 5:e1000334.

18. Lakis S, Papamitsou T, Panagiotopoulou C, Kotakidou R, Kotoula V: AMACR is associated with advanced pathologic risk factors in sporadic colorectal adenomas. World J Gastroenterol 2010, 16:2476-2483.

19. Schmitz KJ, Lang H, Wohlschlaeger J, Reis H, Sotiropoulos GC, Schmid KW, Baba HA: Elevated expression of cyclooxygenase-2 is a negative prognostic factor for overall survival in intrahepatic cholangiocarcinoma. Virchows Arch 2007, 450:135-141.

20. Jiang Z, Li C, Fischer A, Dresser K, Woda BA: Using an AMACR (P504S)/ 34betaE12/p63 cocktail for the detection of small focal prostate carcinoma in needle biopsy specimens. Am J Clin Pathol 2005, 123:231-236.

21. Snover DC: Serrated polyps of the large intestine. Semin Diagn Pathol 2005, 22:301-308.

22. Dorer R, Odze RD: AMACR immunostaining is useful in detecting dysplastic epithelium in Barrett"s esophagus, ulcerative colitis, and Crohn"s disease. Am J Surg Pathol 2006, 30:871-877.

23. Fujimori Y, Fujimori T, Imura J, Sugai T, Yao T, Wada R, Ajioka Y, Ohkura Y: An assessment of the diagnostic criteria for sessile serrated adenoma/ polyps: SSA/Ps using image processing software analysis for Ki67 immunohistochemistry. Diagn Pathol 2012, 7:59.

24. Collado M, Blasco MA, Serrano M: Cellular senescence in cancer and aging. Cell 2007, 130:223-233.

25. Campisi J, d'Adda di Fagagna F: Cellular senescence: when bad things happen to good cells. Nat Rev Mol Cell Biol 2007, 8:729-740.

\section{doi:10.1186/1746-1596-8-178}

Cite this article as: Dayi et al.: Increased expression of a-methylacylcoenzyme A racemase (AMACR; p504s) and p16 in distal hyperplastic polyps. Diagnostic Pathology 2013 8:178.

\section{Submit your next manuscript to BioMed Central and take full advantage of:}

- Convenient online submission

- Thorough peer review

- No space constraints or color figure charges

- Immediate publication on acceptance

- Inclusion in PubMed, CAS, Scopus and Google Scholar

- Research which is freely available for redistribution 